\title{
Sociodemographic and Behavioral Predictors of COVID-19 Vaccine Hesitancy in Pakistan
}

\author{
Osama Al-Wutayd (1D) \\ Rehana Khalil (D) \\ Allah Bachayo Rajar ${ }^{2}$ \\ 'Department of Family and Community \\ Medicine, Unaizah College of Medicine \\ and Medical Sciences, Qassim University, \\ Unaizah, Saudi Arabia; ${ }^{2}$ Department of \\ Community Medicine, Muhammad \\ Medical College, MirpurKhas, Pakistan
}

Correspondence: Osama Al-Wutayd Email o.alwutayd@qu.edu.sa
Background: The current coronavirus disease 2019 (COVID-19) pandemic continues with resurgent second and third waves worldwide. Vaccination is one of several measures that are needed to end this pervasive threat. Pakistan, however, has a relatively low rate of routine vaccine acceptance. Our study aimed to determine the proportion and predictors of COVID19 vaccine hesitancy (VH) among adults in Pakistan.

Methods: An online cross-sectional study was conducted from December 27, 2020 to March 6, 2021. Non-probability sampling was applied to recruit study participants through social media platforms (ie, Facebook and Twitter) and through free messaging services (WhatsApp). Stata 16 was used to generate descriptive statistics and logistic regression models for identifying predictive variables of vaccine hesitancy. A p-value of $<0.05$ was considered strong evidence against the null hypothesis.

Results: Out of 1014 participants, 35.8\% ( $\mathrm{n}=363)$ were hesitant about receiving the COVID-19 vaccine. Reasons for VH included concerns about side effects (42.4\%), belief in conspiracy theories (20.1\%), perceived inefficacy of the vaccine (13.2\%), and perceived protection through precautionary measures (12.6\%). Urban residency (AOR 2.34, 95\% CI 1.54-3.57), reservations about vaccine safety (AOR 3.29, 95\% CI 1.68-6.44), uncertainty about vaccine efficacy (AOR 2.70, 95\% CI 1.50-4.86), failure of the vaccine to reduce hospitalization and death (AOR 6.36, 95\% CI 4.0110.22), and unfelt need for vaccination awareness among public (AOR 2.02, 95\% CI 1.28-3.14) were associated with higher rates of $\mathrm{VH}$. At least one chronic disease (AOR 0.60, 95\% CI 0.39 0.92), knowing someone infected with COVID-19 (AOR 0.56, 95\% CI 0.39-0.81), and trusting information from the ministry of health (AOR $0.64,95 \% \mathrm{CI} 0.41-0.99$ ) and physicians (AOR 0.27 , 95\% CI 0.13-0.53) were found to be associated with lower rates of COVID-19 VH.

Conclusion: More than one third of survey participants were VH. COVID-19 vaccine uptake in Pakistan can be improved through targeted health education strategies and planned interventions that address the barriers identified in the present study.

Keywords: predictors, COVID-19, vaccine, hesitancy, Pakistan

\section{Introduction}

The current coronavirus disease 2019 (COVID-19) pandemic continues with resurgent second and third waves worldwide. Vaccination is one of several measures needed to end this pervasive threat. ${ }^{1-3}$ COVID-19 vaccines are being rolled out globally. Affluent countries have already secured adequate supplies of vaccine, while impoverished nations await their turn. However, policymakers are facing the significant challenge of vaccine hesitancy among their populace. ${ }^{4}$ A number of recent studies have explored the rates of COVID-19 vaccine acceptance and their determinants. $^{5-7}$ One study found reported on the acceptance of COVID-19 vaccines among Chinese healthcare workers compared with the general population. ${ }^{5}$ 
Another study conducted in the United States reported that $20 \%$ of people intended to reject COVID-19 vaccination. ${ }^{6}$ Pakistan's pandemic narrative began in February 2020. Early cases were identified in travelers who returned after visiting shrines in Iran. At present, SARS-Cov-2 has affected 120 million people globally and caused 2.65 million deaths, of which 926,695 and 21,022, respectively, have occurred in Pakistan. ${ }^{4,8,9}$ Pakistan is bordered by India to the East and is likely to be affected by the country's deadly second wave that crippled its healthcare system due to massive increases in caseloads and fatalities. According to the World Health Organization, multiple mutated variants of the novel coronavirus are circulating in India, likely fueling the surge and making a third wave inevitable. If Pakistan does not heed this warning and work to increase vaccine acceptance, it risks long-term cycles of lockdowns, economic damage, and constant fear. ${ }^{10,11}$ Pakistan launched its coronavirus vaccination drive on February 3, 2021, when the first batch of COVID-19 vaccines from China arrived in Pakistan. The vaccine was first administered to healthcare workers treating COVID-19 patients. It was then administered through a countrywide campaign to people over 60 years of age, and is now available to all individuals aged 19 and older. $^{8,9,12}$ The total population of Pakistan is 207.77 million, its nationwide average household size is 6.45 persons, and its average annual population growth rate (1998-2017) at the national level is $2.4 \%$ (growth in urban areas is $2.70 \%$, which is higher than $2.23 \%$ in rural areas). The number of men in the country stands at $51.24 \%$. Its population distribution is $63.56 \%$ rural and $36.44 \%$ urban. The country's literacy rate is $58.92 \%$, and $64 \%$ of the total population is below the age of 30 while $29 \%$ is between 15 and 29 years. ${ }^{13,14}$

Pakistan has a checkered history of child and adult vaccination, public suspicion, and vaccine hesitancy. A notable example of this is the failure to eradicate polio from the country due to conspiracy theories. ${ }^{15}$ Controversies about polio and other vaccines are rooted in the cultural and religious beliefs of Pakistanis. ${ }^{15,16}$ One study conducted in Sindh, a large province in Pakistan, concluded that conspiracies and myths are major barriers to vaccine uptake in the region. ${ }^{17}$ This is consistent with the outcomes of most vaccination campaigns, which are usually affected by public reservations about the efficacy and safety of the vaccines. ${ }^{18-20}$ An estimated $5-10 \%$ of people have strong convictions against vaccines, while a significantly high proportion are "vaccine hesitant"
(VH). Apprehensions about vaccine safety play an essential role in most of these anti-vaccine communities. ${ }^{19,20}$ Johnson et $\mathrm{al}^{21}$ examined the reasons for vaccine refusal and found them to be quite complicated. To our best knowledge, this is the first study on vaccine hesitancy and predictors among the Pakistani population, which is important because vaccine acceptance varies by sociocultural and geographical contexts worldwide Our study aimed to determine the proportion and predictors of COVID-19 vaccine hesitancy (VH) among adults in Pakistan.

\section{Materials and Methods}

This was a cross-sectional study conducted from December 2020 to March 2021 among Pakistanis aged 18 years and older. We framed our questions using information published based on the objectives of the study. $^{7,22,23}$ Two authors (OW and RN) in consultation with experts modified the Questionnaire (s1). The content and face validity of the questionnaire were ensured by experts. The questionnaire was pilot tested on 35 participants, and the final version of the questionnaire was revised and approved by all authors. The finalized questionnaire consisted of five sections: sociodemographic information, information about contracting COVID-19 during the current pandemic, source of information about COVID-19 vaccination, beliefs toward COVID-19 vaccination, and barriers related to COVID-19 vaccination. Monthly family income was grouped into three categories: less than 131 USD (22,000 PKR) per month (low income), 131 USD (22,000 PKR) to 2083 USD (3.5 lakhs PKR) per month (middle income), and more than 2083 USD (3.5 lakhs PKR) per month (high income). ${ }^{24}$ "Vaccine-hesitant" individuals were defined as those who did not intend to be vaccinated. ${ }^{7,22,23,25}$ An electronic questionnaire was distributed through social media, and potential participants were recruited through advertisements on the most popular social media platforms (ie, Facebook and Twitter) and through free messaging services (WhatsApp), starting with the contacts of the author who lived in Pakistan. Participants were also encouraged to pass the link for the questionnaire to their family and friends. Potential participants were reminded to participate via a series of messages over time. The study title, objective, purpose and inclusion/exclusion criteria were described to the participants on the cover page of the survey, and consent to participate was required prior to starting the questionnaire. Sample size was calculated using OpenEpi software. The 
minimum sample size was 829 participants considering $80 \%$ statistical power, 5\% type I error, $69 \%$ among exposed with the outcome, and 58\% among nonexposed with the outcome, ${ }^{26}$ taking into account $30 \%$ expected incomplete responses. The data was analyzed and tabulated using STATA version 16 (StataCorp, College Station, Texas, USA). A descriptive analysis (frequencies and percentages) was performed on sociodemographic characteristics. Simple and multiple logistic regression analyses were used to assess associations between independent variables (potential predictors) and the dependent variable (vaccine hesitancy). Multiple logistic regression included potential predictors with a p-value of $<0.20$ in the simple logistic regression. A p-value of $<0.05$ was considered strong evidence against the null hypothesis.

\section{Results}

\section{Descriptive Characteristics}

A total of 1014 responses were included. Table 1 summarizes the study population's sociodemographics. Almost half of the respondents $(n=444,44 \%)$ were younger than 30 years of age. Males predominated our study population $(\mathrm{n}=536,53 \%)$, and the majority $(\mathrm{n}=682,67 \%)$ of the respondents resided in urban areas of the country. Regarding educational level, almost half ( $\mathrm{n}=533,53 \%)$ of the study respondents had university degrees, and $46 \%$ reported that they were employed (governmental and nongovernmental jobs). The largest proportion of study participants $(n=663,67 \%)$ reported a monthly family income of between 131 USD (22,000 PKR) to 2083 USD (3.5 lakhs PKR) per month (middle income), and $27 \%$ of respondents $(n=279)$ reported a history of one chronic diseases.

\section{Beliefs About COVID-19 Vaccines}

Almost three quarters (72.9\%) of the sample either did not think or were unsure that the vaccine was safe, and more than half (54.9\%) had doubts about the effectiveness of the vaccine. Nevertheless, $40.7 \%$ of participants believed that getting the COVID-19 vaccine was the best way to avoid complications (hospitalization and death). More than three quarters $(81 \%)$ of the study population believed that there was a need for greater public awareness about COVID-19 vaccination in Pakistan (Table 2).

\section{Vaccine Hesitancy and Predictors}

The proportion of respondents considered vaccine hesitant was $35.8 \%(n=363)$.
Table I Participant Sociodemographic Characteristics $(n=10 \mid 4)$

\begin{tabular}{|c|c|c|}
\hline & Number & $\%$ \\
\hline \multicolumn{3}{|l|}{ Age } \\
\hline $18-30$ & 444 & 44 \\
\hline $31-40$ & 229 & 23 \\
\hline $4 I-50$ & 182 & 18 \\
\hline $5 I-60$ & 97 & 10 \\
\hline$>60$ & 62 & 6 \\
\hline \multicolumn{3}{|l|}{ Gender } \\
\hline Female & 478 & 47 \\
\hline Male & 536 & 53 \\
\hline \multicolumn{3}{|l|}{ Residence } \\
\hline Urban & 682 & 67 \\
\hline Rural & 332 & 33 \\
\hline \multicolumn{3}{|l|}{ Education level } \\
\hline Uneducated & 31 & 3 \\
\hline Intermediate & 92 & 9 \\
\hline Secondary & 26 & 3 \\
\hline University & 533 & 52 \\
\hline Higher education & 332 & 33 \\
\hline \multicolumn{3}{|l|}{ Occupation } \\
\hline Employed & 463 & 46 \\
\hline Unemployed & 76 & 8 \\
\hline Housewife & 159 & 16 \\
\hline Students & 316 & 31 \\
\hline \multicolumn{3}{|l|}{ Monthly family income (USD) } \\
\hline$<|3|$ & 200 & 19 \\
\hline$|3|-2083$ & 671 & 67 \\
\hline$>2083$ & 143 & 14 \\
\hline \multicolumn{3}{|l|}{ History of chronic diseases } \\
\hline None & 647 & 64 \\
\hline One chronic diseases & 279 & 27 \\
\hline$\geq$ two chronic diseases & 88 & 9 \\
\hline
\end{tabular}

\section{Sociodemographic Predictors}

Table 3 shows the unadjusted and adjusted associations between sociodemographic predictors and vaccine hesitancy. The unadjusted analysis shows that the odds ratio of vaccine hesitancy was significantly higher among participants between the ages of 31 and 40 years (OR 2.03, 95\% confidence interval [CI] 1.46-2.82, $\mathrm{p}=<0.001$ ), females (OR 1.43, 95\% CI 1.11$1.85, \mathrm{p}=0.006$ ), housewives (OR 1.59, 95\% CI 1.10-2.29, $\mathrm{p}=0.013$ ), and the uneducated (OR 3.36, 95\% CI 1.58-7.17, $\mathrm{p}=0.002)$. In contrast, those with a high reported household income ( $>2083$ USD (PKR $>3.5$ lakhs) were 0.59 times less likely ( $95 \%$ CI: $0.39-0.89, \mathrm{p}=0.012)$ to be VH. The adjusted odds ratio of vaccine hesitancy among participants who lived 
Table 2 Participant Beliefs About the COVID-19 Vaccine $(n=10 \mid 4)$

\begin{tabular}{|l|l|}
\hline Belief & N (\%) \\
\hline Do you think that the COVID-19 vaccine is safe? & $275(27.1)$ \\
Yes & $149(14.7)$ \\
No & $590(58.2)$ \\
\hline Not sure & \\
\hline Do you think that the COVID-19 vaccine is effective? & $337(33.2)$ \\
Yes & $121(11.9)$ \\
No & $556(54.9)$ \\
Not sure & \\
\hline Do you think that the best way to avoid the \\
complications (hospitalization and death) of COVID-I9 \\
is by getting the vaccine? & \\
Yes & $413(40.7)$ \\
No & $212(20.9)$ \\
Not sure & $389(38.4)$ \\
\hline Do you think that greater public awareness is needed & \\
about COVID-19 vaccine? & $821(81)$ \\
Yes & $63(6.2)$ \\
No & $130(12.8)$ \\
Not sure & \\
\hline
\end{tabular}

in urban areas was $2.34(95 \%$ CI 1.54-3.57, $\mathrm{p}=<0.001)$ compared with those residing in rural areas.

\section{Behavioral Predictors}

Table 3 presents results from the logistic regression analysis for potential behavioral factors associated with the COVID-19 vaccine hesitancy among our study respondents. In a multivariable model adjusted for sociodemographic factors, reservations about vaccine safety (AOR 3.29, 95\% CI 1.686.44), uncertainty about its effectiveness (AOR $2.70,95 \% \mathrm{CI}$ $1.50-4.86)$, the failure of a vaccine to reduce complications (hospitalization and death) (AOR 6.36, 95\% CI 4.01-10.22), and unfelt need for vaccination awareness among public (AOR $2.02,95 \%$ CI 1.28-3.14) were associated with higher rates of COVID-19 VH. Participants who knew someone who suffered from COVID-19 infection were 0.56 (95\% CI $0.39-0.81$, $\mathrm{p}=0.002$ ) times less likely to be VH compared with those who did not. Furthermore, participants with a history of at least one chronic disease were 0.60 times less likely to be VH than those without any chronic diseases $(95 \%$ CI 0.39 $0.92, \mathrm{p}=0.02$ ).

\section{Sources of Information About COVID-19 Vaccination}

The majority ( $\mathrm{n}=530,78 \%)$ of the participants who trusted the Ministry of Health $(\mathrm{MoH})$ of Pakistan $(n=738,73 \%)$ as their prime source of information about COVID-19 vaccination were willing to get vaccinated. Of the 895 (88\%) participants who reported confidence in information provided by physicians, 620 (69\%) showed a willingness towards vaccination. The adjusted odds ratio of vaccine hesitancy among participants who trusted Pakistan's ministry of health and physicians were 0.64 (95\% CI $0.41-$ $0.99, \mathrm{p}<0.047)$, and 0.27 (95\% CI $0.13-0.53, \mathrm{p}<0.001)$, respectively, compared with those who reported no trust in these sources (Table 3).

\section{Reasons for COVID-19 Vaccination Hesitancy}

Table 4 lists common reasons for $\mathrm{VH}$ among our study participants. The largest percentage (42.4\%) of hesitant participants expressed concerns about the expected side effects of the vaccines. One fifth $(20.1 \%)$ were of the opinion that conspiracy theories about the vaccine may be true, while others believed that a vaccine could not save them from COVID-19 (13.2\%) or that they did not need the vaccine if they were following precautionary measures (12.6\%). Other reasons for $\mathrm{VH}$ included perceived protection from SARS-Cov-2 due to young age and good health $(6.06 \%)$, fear of needles/syringes $(2.7 \%)$, acquisition of post-infection immunity after recovery from COVID-19 (2.4\%), and insufficient information about the vaccine $(0.3 \%)$.

\section{Constraint Reduction Opportunities}

In response to the question "On which condition would you be more likely to accept the COVID-19 vaccine?", more than one third ( $n=146,40.2 \%)$ out of the 363 vaccine-hesitant participants picked the response "If research studies showed that the vaccine is safe and effective". Approximately $15.1 \%(\mathrm{n}=55,15.1 \%)$ said "If my family or friends get vaccinated", and $(\mathrm{n}=48,13.2 \%)$ said "If my physician recommends it to me". Other responses included, "If it is mandatory to continue my job" ( $\mathrm{n}=19$, $5.2 \%)$, "If it was compulsory by the government (MOH)" $(\mathrm{n}=18,5.1 \%)$, and "If there is a mode other than injection like an oral vaccine" $(\mathrm{n}=13,3.6 \%)$. However, $(\mathrm{n}=48$, $13.2 \%$ ) of the participants were fixed in their decision and replied "I would not take it under any condition". Sixteen respondents (4.4\%) did not specify any condition.

\section{Discussion}

Pakistan, a nation of 207 million people, ${ }^{13}$ is experiencing a sharp rise in COVID-19 cases as it faces a third wave of the novel coronavirus. ${ }^{8}$ Pakistan shares its longest border with 
Table 3 Unadjusted and Adjusted Analysis of Associations Between Potential Predictors and Vaccine Hesitancy

\begin{tabular}{|c|c|c|c|c|c|c|}
\hline \multirow[t]{2}{*}{ Variables } & \multicolumn{2}{|c|}{ Vaccine Hesitancy } & \multirow{2}{*}{$\begin{array}{l}\text { Unadjusted OR } \\
(95 \% \mathrm{CI})\end{array}$} & \multirow[t]{2}{*}{$P$ value } & \multirow{2}{*}{$\begin{array}{l}\text { Adjusted OR } \\
(95 \% \mathrm{Cl})\end{array}$} & \multirow[t]{2}{*}{$P$ value } \\
\hline & $\begin{array}{l}\text { Yes n (\%) } 363 \\
(36)\end{array}$ & $\begin{array}{l}\text { No n (\%) } 65 \text { I } \\
(64)\end{array}$ & & & & \\
\hline \multicolumn{7}{|l|}{ Age, years } \\
\hline $18-30$ & $135(3 \mid)$ & 307 (69) & Reference & & Reference & \\
\hline $31-40$ & $108(47)$ & $|2|(53)$ & $2.03(1.46,2.82)$ & $<0.001$ & $1.74(0.97,3.09)$ & 0.059 \\
\hline $4 I-50$ & $63(35)$ & $119(65)$ & $1.20(0.83,1.74)$ & 0.321 & $1.39(0.75,2057)$ & 0.301 \\
\hline $5 I-60$ & $34(35)$ & $63(65)$ & $1.23(0.77,1.95)$ & 0.387 & $1.84(0.85,3.98)$ & 0.124 \\
\hline$>60$ & $23(37)$ & $39(63)$ & I.34 $(0.77,2.33)$ & 0.299 & I.II $(0.35,3.55)$ & 0.855 \\
\hline \multicolumn{7}{|l|}{ Gender } \\
\hline Female & $192(40)$ & $286(60)$ & $1.43(1.11,1.85)$ & 0.006 & $1.24(0.83,1.85)$ & 0.294 \\
\hline Male & $|7|(32)$ & $365(68)$ & Reference & & Reference & \\
\hline \multicolumn{7}{|l|}{ Residence } \\
\hline Urban & $253(37)$ & $424(63)$ & $1.22(0.93,1.61)$ & 0.158 & $2.34(1.54,3.57)$ & $<0.001$ \\
\hline Rural & $109(33)$ & $223(67)$ & Reference & & Reference & \\
\hline \multicolumn{7}{|l|}{ Education level } \\
\hline Uneducated & $20(65)$ & II (35) & $3.36(1.58,7.17)$ & 0.002 & $1.88(0.55,6.37)$ & 0.312 \\
\hline Intermediate & $30(33)$ & $62(67)$ & $0.89(0.56,1.43)$ & 0.645 & $0.94(0.47,1.86)$ & 0.857 \\
\hline Secondary & $16(62)$ & $10(38)$ & $2.96(1.32,6.65)$ & 0.009 & $2.69(0.85,8.49)$ & 0.091 \\
\hline University & $187(35)$ & $346(65)$ & Reference & & Reference & \\
\hline Higher education & $110(33)$ & $222(67)$ & $0.92(0.69,1.22)$ & 0.557 & $1.10(0.69,1.75)$ & 0.671 \\
\hline \multicolumn{7}{|l|}{ Occupation } \\
\hline Employed & $164(35)$ & $299(65)$ & Reference & & Reference & \\
\hline Unemployed & $3 I(4 I)$ & $45(59)$ & $1.26(0.77,2.06)$ & 0.367 & $1.13(0.50,2.53)$ & 0.776 \\
\hline Housewife & $74(47)$ & $85(53)$ & $1.59(1.10,2.29)$ & 0.013 & $0.84(0.43, I .61)$ & 0.596 \\
\hline Students & $94(30)$ & $222(70)$ & $0.77(0.57,1.05)$ & 0.099 & $0.82(0.45,1.49)$ & 0.513 \\
\hline \multicolumn{7}{|c|}{ Monthly family income (USD) } \\
\hline$<|3|$ & $248(37)$ & $415(63)$ & Reference & & Reference & \\
\hline$|3|-2083$ & $73(38)$ & $118(62)$ & $1.04(0.74,1.44)$ & 0.838 & $0.99(0.61,1.64)$ & 0.987 \\
\hline$>2083$ & $35(26)$ & $100(74)$ & $0.59(0.39,0.89)$ & 0.012 & $0.62(0.36,1.05)$ & 0.076 \\
\hline \multicolumn{7}{|c|}{ History of chronic diseases } \\
\hline None & $239(37)$ & $408(63)$ & Reference & & Reference & \\
\hline One chronic diseases & $98(35)$ & $|8|(65)$ & $0.92(0.69,1.24)$ & 0.599 & $0.60(0.39,0.92)$ & 0.020 \\
\hline$\geq$ two chronic diseases & $26(30)$ & $62(70)$ & $0.72(0.44,1.16)$ & 0.177 & $0.59(0.28,1.25)$ & 0.167 \\
\hline \multicolumn{7}{|c|}{ Did you get COVID-19? } \\
\hline No & $294(37)$ & $502(63)$ & Reference & & Reference & \\
\hline Yes & $67(3 \mathrm{I})$ & $149(69)$ & $0.77(0.56,1.06)$ & 0.108 & $1.03(0.66,1.60)$ & 0.908 \\
\hline \multicolumn{7}{|c|}{ Did anyone in your contacts suffer from covid-19? } \\
\hline No & $190(48)$ & $207(52)$ & Reference & & Reference & \\
\hline Yes & $173(28)$ & $444(72)$ & $0.42(0.33,0.55)$ & $<0.001$ & $0.56(0.39,0.81)$ & 0.002 \\
\hline
\end{tabular}


Table 3 (Continued).

\begin{tabular}{|c|c|c|c|c|c|c|}
\hline \multirow[t]{2}{*}{ Variables } & \multicolumn{2}{|c|}{ Vaccine Hesitancy } & \multirow{2}{*}{$\begin{array}{l}\text { Unadjusted OR } \\
(95 \% \mathrm{CI})\end{array}$} & \multirow[t]{2}{*}{ P value } & \multirow{2}{*}{$\begin{array}{l}\text { Adjusted OR } \\
(95 \% \mathrm{Cl})\end{array}$} & \multirow[t]{2}{*}{$\mathbf{P}$ value } \\
\hline & $\begin{array}{l}\text { Yes n (\%) } 363 \\
(36)\end{array}$ & $\begin{array}{l}\text { No n (\%) 65 I } \\
(64)\end{array}$ & & & & \\
\hline \multicolumn{7}{|c|}{ Do you trust information given by Ministry of Health? } \\
\hline No & $154(56)$ & $|2|(44)$ & Reference & & Reference & \\
\hline Yes & $208(28)$ & $530(72)$ & $0.3 \mathrm{I}(0.23,0.4 \mathrm{I})$ & $<0.001$ & $0.64(0.41,0.99)$ & 0.047 \\
\hline \multicolumn{7}{|c|}{ Do you trust information given by physicians? } \\
\hline No & $86(74)$ & $30(26)$ & Reference & & Reference & \\
\hline Yes & $275(31)$ & $620(69)$ & $0.15(0.09,0.24)$ & $<0.001$ & $0.27(0.13,0.53)$ & $<0.001$ \\
\hline \multicolumn{7}{|c|}{ Do you trust information given by news channels? } \\
\hline No & $179(40)$ & $267(60)$ & Reference & & Reference & \\
\hline Yes & $184(32)$ & $384(68)$ & $0.71(0.55,0.93)$ & 0.011 & $0.78(0.52,1.18)$ & 0.245 \\
\hline \multicolumn{7}{|c|}{ Do you trust information given by social media? } \\
\hline No & $201(34)$ & $388(66)$ & Reference & & Reference & \\
\hline Yes & $162(38)$ & $263(62)$ & $1.19(0.92,1.54)$ & 0.191 & $1.37(0.92,2.03)$ & 0.118 \\
\hline \multicolumn{7}{|c|}{ Do you think that COVID-19 vaccine is safe? } \\
\hline Yes & $18(7)$ & $257(93)$ & Reference & & Reference & \\
\hline No & $345(47)$ & $393(53)$ & $12.5(7.61,20.6)$ & $<0.001$ & $3.29(1.68,6.44)$ & 0.001 \\
\hline \multicolumn{7}{|c|}{ Do you think that COVID-19 vaccine is effective? } \\
\hline Yes & $24(7)$ & $311(93)$ & Reference & & Reference & \\
\hline No & $339(50)$ & $340(50)$ & $12.9(8.3,20.1)$ & $<0.001$ & $2.70(1.50,4.86)$ & 0.001 \\
\hline \multicolumn{7}{|c|}{ Do you think that the best way to avoid hospitalization and death is by getting the vaccine? } \\
\hline Yes & $29(7)$ & $380(93)$ & Reference & & Reference & \\
\hline No & $334(55)$ & $269(45)$ & $16.3(10.8,24.5)$ & $<0.001$ & $6.39(4.01,10.22)$ & $<0.001$ \\
\hline \multicolumn{7}{|c|}{ Do you think that greater public awareness is needed about COVID-19 vaccine? } \\
\hline Yes & $235(29)$ & $589(7 I)$ & Reference & & Reference & \\
\hline No & $128(67)$ & $62(33)$ & $5.17(3.69,7.26)$ & $<0.001$ & $2.02(1.28,3.14)$ & 0.003 \\
\hline
\end{tabular}

Table 4 Reasons for COVID-19 Vaccine Hesitancy Cited by Study Participants $(n=363)$

\begin{tabular}{|l|l|}
\hline Reason & $\mathbf{n}(\%)$ \\
\hline Concerns about the vaccine's side effects & $154(42.4)$ \\
Concerns on conspiracy theories about COVID-19 vaccine & $73(20.1)$ \\
Belief that the vaccine cannot save from COVID-19 infection & $48(13.2)$ \\
No need of vaccine because all the precautions are ensured (washing hands, wearing mask and gloves) & $46(12.6)$ \\
No need of vaccine because of perceived protection of participant from COVID-19 due to their young age and good health & $22(6.06)$ \\
Fear of needles/syringes & $10(2.7)$ \\
Perceived acquisition of immunity against COVID-I9 virus after contracting and recovering from COVID-I9 infection (in past months) & $9(2.4)$ \\
Wait and see the effects of vaccines in others/Insufficient information about vaccine & 1 (0.3) \\
\hline
\end{tabular}


the second-most affected country by SARS-Cov- 2 in the world, India. Indian hospitals are scrambling for beds and oxygen in response to its deadly second surge, which can pose an additional threat to Pakistan. ${ }^{10,11}$ However, vaccine uptake in Pakistan slow due to concerns regarding the safety and efficacy of the vaccine. ${ }^{9}$ Studies are being performed all over the world to assess COVID-19 vaccine hesitancy, ${ }^{5-7,18}$ and vaccine acceptance/hesitancy rates vary between countries. ${ }^{6,7}$ An approximate $20-25 \%$ hesitancy rate among Canadian and American adults was identified in a study by Taylor et $\mathrm{al}^{27}$ in May 2020. Rates of COVID-19 vaccine hesitancy in Italy and France were found to be $41 \%$ and $26 \%$, respectively. ${ }^{28,29}$ A global survey conducted in 19 countries revealed a less than 55\% acceptance rate in Russia and the highest rate of acceptance (90\%) in China. ${ }^{7}$ A vaccine acceptance rate of $>90 \%$ was reported in a study in Indonesia. $^{22}$ Our study results showed a higher rate of vaccine hesitancy (35.8\%) in Pakistan than the USA $(20 \%)^{6}$ and Egypt (27\%). ${ }^{30}$ Conversely, our study population's vaccine hesitancy was lower than that of Australia $(41 \%)^{31}$ and KSA $(55.3 \%){ }^{23}$ However, our result is equal to that found by Mohammed Al-Mohaithef et $\mathrm{al}^{26}$ in their survey of KSA $(35.3 \%)$. Beliefs play a pivotal role in vaccine acceptance. Our study results identified significant doubts about the safety and efficacy of the COVID-19 vaccine. Our findings are in agreement with studies conducted in different countries that reported safety and efficacy as prime concerns regarding the COVID-19 vaccine. ${ }^{22,32-35}$ Likewise, surveys that probed the reasons for COVID-19 vaccine refusal reported that concerns over efficacy and safety were among the leading reasons provided by study participants. ${ }^{36-39}$ In Pakistan, one potential explanation for safety issues related to COVID-19 vaccine and vaccine hesitancy is the vaccine's Chinese origin. The main bulk of the nationwide inoculation drive in Pakistan was the Chinese vaccine, which was provided in addition to other vaccines from the World Health Organization's COVAX program. Kreps et al studied vaccine attributes associated with vaccine choice and found that respondents were less willing to receive COVID-19 vaccines developed in nations other than the United States. The Chinese vaccine was particularly unpopular after vaccines developed in the UK. ${ }^{40}$

A recently published study of US healthcare workers by Shekhar et $\mathrm{al}^{41}$ reported a higher rate of expected vaccine hesitancy among females compared with males. However, this is inconsistent with our findings, as our study found no association between gender and vaccine hesitancy. In agreement with the findings of a 2011 systematic review by Wilson et al, ${ }^{42}$ which showed no consistent association between participant age and vaccine uptake, our study also found no significant association between hesitancy rate and participant age. Contemporary research studies on COVID-19 vaccine hesitancy ${ }^{36,43,44}$ showed that rural residents were less likely to get the COVID-19 vaccine compared with urban residents. However, our study found that urban dwellers were twice (2.34 times) as likely to be vaccine hesitant compared with their rural counterparts. A possible explanation for this could be widespread misinformation distributed through social media over the past year. Urban dwellers are at a much higher risk of receiving misinformation because of their better internet connections than rural dwellers, and therefore have a higher chance of believing conspiracy theories. In our study, the rates of vaccine hesitancy among those who knew someone (family members, etc.) who had suffered from COVID19 were 0.56 times (95\% CI $0.39-0.81$ ) that of those whose contacts had not contracted SARS-Cov-2. Participants with a history of one chronic disease were 0.60 times as likely to be COVID-19 vaccine hesitant, which might be related to their perception about the higher morbidity and mortality of people with chronic diseases. ${ }^{45}$ In the present study, the rates of vaccine hesitancy were lowest among participants who relied on vaccine information provided by official sources, including the ministry of health and medical doctors $(0.64$, and 0.27 , times, respectively, less), compared with those who reported no trust in these sources. These results are similar to findings from Bish et al, ${ }^{46}$ who reported that people who received information about vaccination from official health sources were more likely to get vaccinated than those who trusted unofficial sources. ${ }^{46}$ Similarly, Earnshaw et $\mathrm{al}^{47}$ reported that doctors were the most trusted source of information about COVID-19 vaccines by those who intended to get vaccinated against SARS-Cov-2. The foremost concern among participants in the present work was about the side effects of the vaccine $(43.4 \%)$, which is in agreement with the findings of $\mathrm{Abbas}$ et $\mathrm{al}^{17}(59.7 \%)$ and the results reported by the aforementioned study by Bish et al. ${ }^{46}$ The secondmost predominant fear expressed by our study population was a belief in conspiracy theories about COVID-19 vaccines $(19.7 \%)$. This finding is also consistent with the conclusion of the recent study by Abbas et al ${ }^{17}$ conducted in Sindh province of Pakistan. Multiple conspiracy theories about the COVID-19 pandemic have been spreading rapidly around the world. ${ }^{48,49}$ These conspiracy beliefs are 
rooted partly in medical mistrust or a general suspicion of and lack of confidence in medical organizations and providers. ${ }^{16}$ Other significant barriers against vaccination included beliefs that a vaccine could not save individuals from SARS-Cov-2, and that there was no need to get vaccinated if precautionary measures were being taken. ${ }^{17}$

This study has a number of limitations. First, it is a snapshot of the intentions of participants to get vaccinated against SARS-Cov-2, but public intentions may change over time. Secondly, we used non-probability sampling technique, which may not accurately reflect a cross-section of the research population. It can still be considered as a good starting point for further expansion towards population based or nationwide representative studies. Thirdly, since this questionnaire was distributed online using social media platforms, there is a risk of selection bias due to variable quality of internet access across different areas of the country, and those spending time on social media during the pandemic likely have different attitudes towards the vaccine compared with those who did not responding to a web-based surveys. There may also be social desirability bias in reporting an intent to get vaccinated against SARS-Cov-2. Another limitation is that our study participants were predominantly younger than 40 years old, educated, and employed, and therefore may not be representative of the actual Pakistani population. Finally, our results provide some insight into vaccine hesitancy in Pakistan, but require further exploration with a largescale robust follow-up study.

\section{Conclusion}

The results of the current study represent an alarming situation for policymakers in Pakistan. Approximately 35\% of participants were hesitant to accept COVID-19 vaccination. Perceived failure of the vaccine's ability to reduce hospitalization and death, concerns about vaccine safety and effectiveness, urban residents, and unfelt need for vaccination were the most commonly cited reasons for vaccine hesitation. Further larger studies are needed to verify these findings and to better understand the different demographic groups that are vaccine hesitant.

\section{Data Sharing Statement}

The data that support the findings of this study are available from the first author upon request.

\section{Ethics Approval}

Ethical approval was received from the Ethics Committee at Muhammad Medical College, Pakistan (reference no. 022).
All procedures performed in the study were in accordance with the ethical standards of the institutional and/or national research committee and with the 1964 Helsinki declaration and its later amendments. Informed consent was collected from each participant before taking part in the research study.

\section{Acknowledgments}

The researchers would like to thank the Deanship of Scientific Research, Qassim University for funding the publication of this project.

\section{Disclosure}

All authors declare that they have no competing interests in this work.

\section{References}

1. Novel Coronavirus (2019-nCoV) situation report - 121 January 2020 [document on the Internet]. World Health Organization; 2020. Available from: https://www.who.int/docs/default-source/coronavir use/situation-reports/20200121-sitrep-1-2019-ncov.pdf. Accessed March 14, 2021.

2. Huang C, Wang Y, Li X, et al. Clinical features of patients infected with 2019 novel coronavirus in Wuhan, China. Lancet. 2020;395 (10223):497-506. doi:10.1016/S0140-6736(20)30183-5

3. Murphy J, Vallières F, Bentall RP, et al. Psychological characteristics associated with COVID-19 vaccine hesitancy and resistance in Ireland and the United Kingdom. Nat Commun. 2021;12(1):29. doi:10.1038/s41467-020-20226-9

4. WHO Coronavirus (COVID-19) Dashboard [homepage on the Internet]. World Health Organization; 2021. Available from: https:// covid19.who.int/. Accessed March 14, 2021.

5. Fu C, Wei Z, Pei S, Li S, Sun X, Liu P. Acceptance and preference for COVID-19 vaccination in health-care workers (HCWs) (preprint). medRxiv. 2020. doi:10.1101/2020.04.09.20060103

6. Thunstrom L, Ashworth M, Finnoff D, Newbold S. Hesitancy towards a COVID-19 vaccine and prospects for herd immunity. SSRN. 2020. doi:10.2139/ssrn.3593098.

7. Lazarus JV, Ratzan SC, Palayew A, et al. A global survey of potential acceptance of a COVID-19 vaccine. Nat Med. 2021;27(2):225-228. doi:10.1038/s41591-020-1124-9

8. Covid-19 dashboard [homepage on the Internet]. Government of Pakistan; 2021. Available from: https://covid.gov.pk. Accessed March 14, 2021.

9. National command and operation center [homepage on the Internet]. Government of Pakistan; 2021. Available from: https://ncoc.gov.pk/. Accessed March 14, 2021.

10. Jain VK, Iyengar KP, Vaishya R. Differences between first wave and second wave of COVID-19 in India. Diabetes Metab Syndr. 2021;15(3):1047-1048. doi:10.1016/j.dsx.2021.05.009

11. Bhuyan A. Experts criticise India's complacency over COVID-19. Lancet. 2021;397(10285):1611-1612. doi:10.1016/S0140-6736(21) 00993-4

12. Phase II: Pakistan to start vaccinating citizens over 65 years on receiving $2.8 \mathrm{~m}$ doses around March 2, says SAPM [article on the Internet]. Dawn. Available from: https://www.dawn.com/news/ 1608067. Accessed March 14, 2021.

13. Pakistan Bureau of Statistics (PBS). 6th Population \& housing census 2017. Available from: https://www.pbs.gov.pk/content/final-resultscensus-2017. Accessed August 23, 2021. 
14. National human development report. United Nations Development Programme (UNDP) Pakistan. Available from: http://hdr.undp.org/en/ content/unleashing-potential-young-pakistan. Accessed August 25, 2021

15. Ali M, Ahmad N, Khan H, Ali S, Akbar F, Hussain Z. Polio vaccination controversy in Pakistan. Lancet. 2019;394(10202):915-916. doi:10.1016/S0140-6736(19)32101-4

16. Khan TM, Chiau LM. Polio vaccination in Pakistan: by force or by volition? Lancet. 2015;386:1733.

17. Abbas Q, Mangrio F, Kumar S. Myths, beliefs, and conspiracies about COVID-19 vaccines in Sindh, Pakistan: an online cross-sectional survey (preprint). Authorea. 2021. doi:10.22541/ au.161519250.03425961/v1

18. Black S, Rappuoli R. A crisis of public confidence in vaccines. Sci Transl Med. 2010;2(61):61 mr1. doi:10.1126/scitranslmed.3001738

19. Poland GA, Jacobson RM, Ovsyannikova IG. Trends affecting the future of vaccine development and delivery: the role of demographics, regulatory science, the anti-vaccine movement, and vaccinomics. Vaccine. 2009;27(25-26):3240-3244. doi:10.1016/j. vaccine.2009.01.069

20. MacDonald NE, Smith J, Appleton M. Risk perception, risk management and safety assessment: what can governments do to increase public confidence in their vaccine system? Biologicals. 2012;40 (5):384-388. doi:10.1016/j.biologicals.2011.08.001

21. Johnson NF, Velásquez N, Restrepo NJ, et al. The online competition between pro- and anti-vaccination views. Nature. 2020;582 (7811):230-233. doi:10.1038/s41586-020-2281-1

22. Harapan H, Wagner AL, Yufika A, et al. Acceptance of a COVID-19 vaccine in Southeast Asia: a cross-sectional study in Indonesia. Front Public Health. 2020;8:381. doi:10.3389/fpubh.2020.00381

23. Magadmi RM, Kamel FA. Beliefs and barriers associated with COVID-19 vaccination among the general population in Saudi Arabia (preprint). BMC Public Health. 2021;21(1):1-8. doi: $10.21203 /$ rs.3.rs-48955/v1

24. How much money does a person working in Pakistan make? Average salary in Pakistan; 2021. Available from: http:/www.salaryexplorer.com/ salary-survey.php?loc=164\&loctype=1. Accessed August 24, 2021.

25. Kennedy J. Vaccine hesitancy: a growing concern. Pediatr Drugs. 2020;22(2):105-111. doi:10.1007/s40272-020-00385-4

26. Al-Mohaithef M, Padhi BK. Determinants of COVID-19 vaccine acceptance in Saudi Arabia: a web-based national survey. $J$ Multidiscip Healthc. 2020;13:1657-1663. doi:10.2147/JMDH S276771

27. Taylor S, Landry CA, Paluszek MM, Groenewoud R, Rachor GS, Asmundson GJG. A proactive approach for managing COVID-19: the importance of understanding the motivational roots of vaccination hesitancy for SARS-CoV2. Front Psychol. 2020;11:575950. doi:10.3389/fpsyg.2020.575950

28. Graffigna G, Palamenghi L, Boccia S, Barello S. Relationship between citizens' health engagement and intention to take the COVID-19 vaccine in Italy: a mediation analysis. Vaccines. 2020;8 (4):576. doi:10.3390/vaccines 8040576

29. Peretti-Watel P, Seror V, Cortaredona S; COCONEL Group. A future vaccination campaign against COVID-19 at risk of vaccine hesitancy and politicisation. Lancet Infect Dis. 2020;20(7):769-770. doi:10.1016/S1473-3099(20)30426-6

30. Abdelhafiz AS, Mohammed Z, Ibrahim ME, et al. Knowledge, perceptions, and attitude of Egyptians towards the novel coronavirus disease (COVID-19). J Community Health. 2020;45(5):881-890. doi:10.1007/s10900-020-00827-7

31. Edwards B, Biddle N, Gray M, Sollis K. COVID-19 vaccine hesitancy and resistance: correlates in a nationally representative longitudinal survey of the Australian population (preprint). PloS One. 2021;16(3):e0248892. doi:10.1101/2020.11.13.20231480
32. Syed Alwi SAR, Rafidah E, Zurraini A, et al. A survey on COVID-19 vaccine acceptance and concern among Malaysians. BMC Public Health. 2021;21(1):1129. doi:10.1186/s12889-021-11071-6

33. Neumann-Böhme S, Varghese NE, Sabat I, et al. Once we have it, will we use it? A European survey on willingness to be vaccinated against COVID-19. Eur J Health Econ. 2020;21(7):977-982. doi:10.1007/s10198-020-01208-6

34. Lin C, Tu P, Beitsch LM. Confidence and receptivity for covid-19 vaccines: a rapid systematic review. Vaccines. 2020;9(1):16. doi:10.3390/vaccines9010016

35. Callaghan T, Moghtaderi A, Lueck JA, et al. Correlates and disparities of intention to vaccinate against COVID-19. Soc Sci Med. 2021;272:113638. doi:10.1016/j.socscimed.2020.113638

36. Fisher KA, Bloomstone SJ, Walder J, et al. Attitudes toward a potential sars-cov-2 vaccine: a survey of U.S. adults. Ann Intern Med. 2020;173(12):964-973. doi:10.7326/M20-3569

37. Yoda T, Katsuyama H. Willingness to receive covid-19 vaccination in Japan. Vaccine. 2021;9(1):48. doi:10.3390/vaccines9010048

38. Ruiz JB, Bell RA. Predictors of intention to vaccinate against COVID-19: results of a nationwide survey. Vaccine. 2021;39 (7):1080-1086. doi:10.1016/j.vaccine.2021.01.010

39. Yigit M, Ozkaya-Parlakay A, Senel E. Evaluation of COVID-19 vaccine refusal in parents. Pediatr Infect Dis J. 2021;40(4):e134e136. doi:10.1097/INF.0000000000003042

40. Kreps S, Prasad S, Brownstein JS, et al. Factors associated with US adults' likelihood of accepting COVID-19 vaccination [published correction appears in JAMA Netw Open. 2020 Nov 2;3(11): e2030649]. JAMA Netw Open. 2020;3(10):e2025594. doi:10.1001/ jamanetworkopen.2020.25594

41. Shekhar R, Sheikh AB, Upadhyay S, et al. COVID-19 vaccine acceptance among health care workers in the United States. Vaccines. 2021;9(2):119. doi:10.3390/vaccines9020119

42. Wilson K, Nguyen HH, Brehaut H. Acceptance of a pandemic influenza vaccine: a systematic review of surveys of the general public. Infect Drug Resist. 2011;4:197. doi:10.2147/IDR.S23174

43. Khubchandani J, Sharma S, Price JH, et al. Covid-19 vaccination hesitancy in the United States: a rapid national assessment. J Community Health. 2021;46(2):270-277. doi:10.1007/s10900-020-00958-x

44. Reiter PL, Pennell ML, Katz ML. Acceptability of a covid-19 vaccine among adults in the United States: How many people would get vaccinated? Vaccine. 2020;38(42):6500-6507. doi:10.1016/j. vaccine.2020.08.043

45. Yang J, Zheng Y, Gou X, et al. Prevalence of comorbidities in the novel Wuhan coronavirus (COVID-19) infection: a systematic review and meta-analysis. Int $J$ Infect Dis. 2020;94:91-95. doi:10.1016/j. ijid.2020.03.017

46. Bish A, Yardley L, Nicoll A, Michie S. Factors associated with uptake of vaccination against pandemic influenza: a systematic review. Vaccine. 2011;29(38):6472-6484. doi:10.1016/j.vaccine.2011.06.107

47. Earnshaw VA, Eaton LA, Kalichman SC, Brousseau NM, Hill EC, Fox AB. COVID-19 conspiracy beliefs, health behaviors, and policy support. Transl Behav Med. 2020;10(4):850-856. doi:10.1093/tbm/ ibaa090

48. Biddlestone M, Green R, Douglas KM. Cultural orientation, power, belief in conspiracy theories, and intentions to reduce the spread of COVID-19. Br J Soc Psychol. 2020;59(3):663-673. doi:10.1111/bjso.12397

49. Georgiou N, Delfabbro P, Balzan R. COVID-19-related conspiracy beliefs and their relationship with perceived stress and pre-existing conspiracy beliefs. Pers Individ Dif. 2020;166:110201. doi:10.1016/j. paid.2020.110201 


\section{Publish your work in this journal}

The Journal of Multidisciplinary Healthcare is an international, peerreviewed open-access journal that aims to represent and publish research in healthcare areas delivered by practitioners of different disciplines. This includes studies and reviews conducted by multidisciplinary teams as well as research which evaluates the results or conduct of such teams or healthcare processes in general. The journal covers a very wide range of areas and welcomes submissions from practitioners at all levels, from all over the world. The manuscript management system is completely online and includes a very quick and fair peer-review system. Visit http://www.dovepress.com/testimonials. php to read real quotes from published authors. 